\title{
ADULT PANCREATOBLASTOMA: A RARE ENTITY
}

\author{
G. Ray ${ }^{1}$, S. P. Venkatesh ${ }^{2}$, S. Ilayalvan ${ }^{3}$, S. Sowmya ${ }^{4}$, E. Nidhya ${ }^{5}$
}

\section{HOW TO CITE THIS ARTICLE:}

G. Ray, S. P. Venkatesh, S. Ilayalvan, S. Sowmya, E. Nidhya."Adult Pancreatoblastoma: A Rare Entity". Journal of Evolution of Medical and Dental Sciences 2014; Vol. 3, Issue 46, September 22; Page: 11292-11295,

DOI: $10.14260 /$ jemds/2014/3473

\begin{abstract}
Pancreatoblastoma is a rare tumor of neuroendocrine origin affecting paediatric age group. It is an extremely rare neoplasm of adults. Patients with pancreatoblastoma present with complaints of abdominal pain and distension. Clinically diagnosis is usually of a retroperitoneal sarcoma or tumor of colon. This tumor is generally detected accidentally during laparotomy and diagnosis is confirmed by histopathology. The presence of squamoid corpuscles with a morular appearance and acinar differentiation is the most characteristic feature of this tumor. In this article we present one such rare case of pancreatoblastoma in a 50yr old lady.
\end{abstract}

KEYWORDS: Pancreotoblastoma; Adult; Pancreatic cancer; Histopathology.

INTRODUCTION: The term pancreatoblastoma was introduced in 1977 by Horie et al. to describe a rare pancreatic tumor of childhood, previously known as infantile carcinoma of the pancreas. The histological features are similar to the pancreatic tissue of fetus at approximately at $7^{\text {th }}$ week of gestation. ${ }^{1-2}$ A pancreatoblastoma typically manifests in children between 1-8yrs of age. ${ }^{3}$ It may also affect neonates and elderly. . $^{4}$

Nevertheless, it is extremely rare in adults. In 1986, Palosaari et al described the first case in an adult. Men are more commonly affected than women. It is clinically occult and is large at the time of presentation. Clinical features are typically due to mass effect like abdominal pain, weight loss, satiety, vomiting, jaundice and constipation. ${ }^{8-14}$ Here we describe a case where the preoperative diagnosis was retroperitoneal sarcoma but was later confirmed to be pancreatoblastoma on histopathological examination.

CASE REPORT:A 50yr old female presented with pain abdomen, mild distention of abdomen and constipation, on and off for the past two months. She also had loss of weight and loss of appetite. On examination she was thin built, afebrile, pale and there was mild distention of abdomen. On examination a palpable abdominal mass was present in the left hypochondrium which was hard in consistency, moving with respiration, had irregular borders, non-tender and ballotable but not bimanually palpable.

Clinically differential diagnosis of retroperitoneal sarcoma or carcinoma of transverse and descending colon was made. Laboratory investigations were within normal limits except for haemoglobin of $7 \mathrm{gms} / \mathrm{dl}$. Ultrasound abdomen revealed $8.5 \times 6.5 \times 8.6 \mathrm{~cm}$ sized, ovulated heterogeneous mass lesion seen in the left lumbar region, inferior to the left kidney. The lesion appeared to be medial to the descending colon, with no demonstrable fat plane in between. The tail of pancreas was not visualized separately. The lesion was vascularized and spleen appeared encased. Few para aortic and celiac lymph nodes were seen. Diagnosis was confirmed by CT.

On laparotomy a necrotic nodular mass was found to be arising from the tail of the pancreas, encasing the splenic vein and infiltrating the root of mesentry and transverse mesocolon (Fig 1). 


\section{CASE REPORT}

Large Omental and mensenteric deposits were found (Fig. 2). Debulking of the tumor along with distal pancreatectomy, splenectomy and resection of transverse colon was done. Histopathology of the resected specimen confirmed a malignant epithelial tumour.

The microscopic features demonstrated squamoid corpuscles and acinar differentiations which are classical features of pancreatoblastoma (Fig. 3). Immunocytochemistry was used for identifying acinar differentiation.Omentum showed multiple tumor deposits. The patient was referred to regional cancer institute for chemotherapy and was on follow up till she died 2 years after diagnosis.

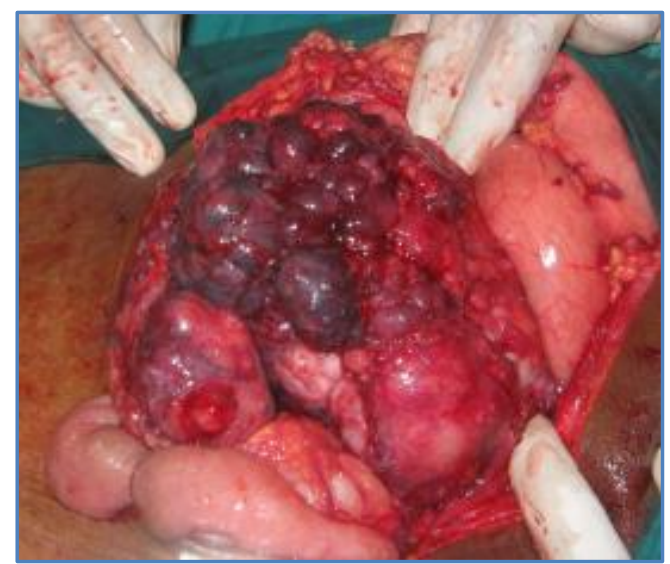

Fig. 1: Pancreatic tumour

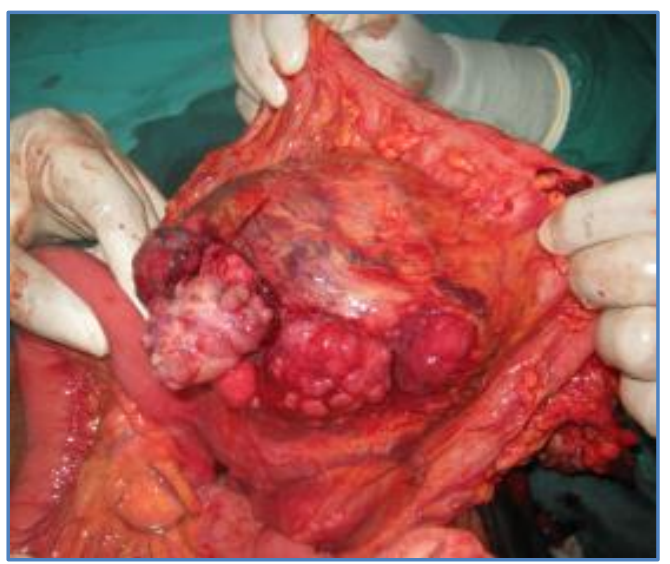

Fig. 2: Mesenteric \&Omental deposits

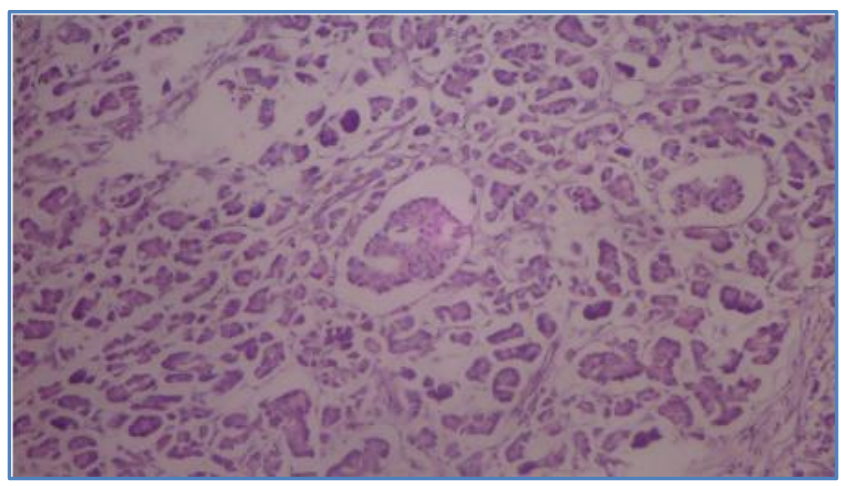

Fig. 3: Histopathology

DISCUSSION: Pancreatoblastoma accounts for $0.5 \%$ of exocrine tumors of pancreas, with highest incidence in the first decade of life with a predilection for males and Asians. Differential diagnosis includes nonfunctional pancreatic endocrine tumor, acinar cell carcinoma, solid pseudopapillary tumor and adenocarcinoma ${ }^{15}$. Usually adult pancreatoblastomas are slow growing and large, ranging between $1.5 \mathrm{~cm}$ and $20 \mathrm{~cm}$ with majority larger than $8 \mathrm{~cm} .{ }^{6}$ Approximately half of them are located in the pancreatic head. ${ }^{6-9 \& 12}$ 
Few cases have been reported to arise from tail.6,10\&13 Du et al have reported a case located at ampula of Vater and Zhu et al have reported a case in the body of pancreas. Distant metastasis commonly involves liver (26\%) and then lymph nodes (14\%). CT scan shows a well circumscribed, heterogenous mass with features suggestive of peripheral vascularity and viability with areas of central necrosis. ${ }^{15}$

Histologically the presence of squamoid corpuscles is the most characteristic feature besides acinar differentiation. Treatment includes surgical resection, followed by adjuvant chemotherapy or radiotherapy because of high metastatic potential of the tumor. But prognosis is poor and more than half of them die within 3yrs of initial diagnosis. ${ }^{6}$

An atypical case has been described by Balasundaram et al where the tumor was small $(3.6 \mathrm{~cm})$ with extensive metastasis to liver, lungs and breast. Besides this histologically there was absence of acinar component. Our patient was a female, with the tumor involving the root of pancreas, spleen and transverse colon. Diagnosis was possible only by histopathological picture ofsquamoid corpuscles and acinar differentiations.She had no distant metastasis at the time of diagnosis but died 2 years post diagnosis substantiating the high malignant potential of the tumour.

CONCLUSION:Adult pancreatoblastoma is usually a diagnostic challenge and also can have an atypical clinical picture and a small primary with extensive metastasis to unusual sites as well as without metastasis as in our case. Given its rarity, a high index of suspicion is required to correctly diagnose this condition and also well prepared while exploring a retroperitoneal mass in the epigastric region.

\section{REFERENCES:}

1. Horie A, Yano Y, Kotoo Y. Morphogenesis of pancreatoblastoma, infantile carcinoma of the pancreas: report of two cases. Cancer 1977; 39: 247-254.

2. Cubilla AL, Fitzgerald PJ. Classification of pancreatic cancer (nonendocrine). Mayo ClinProc 1979; 54: 449-458.

3. Du E, Katz M, Weidner N, et al. Ampullarypancreatoblastoma in an elderly patient: A case report and review of the literature. Arch Pathol Lab Med 2003; 127: 1501-1505.

4. Kloppel G, Maillet B. Classification and staging of pancreatic nonendocrinetumors. RadiolClin North Am 1989; 27: 105-119.

5. Friedman AC, Edmonds PR. Rare pancreatic malignancies. RadiolClin North Am 1989; 27: 177 190.

6. Klimstra DS, Wenig BM, Adair CF, et al. Pancreatoblastoma. A clinicopathologic study and review of the literature. Am J SurgPathol 1995; 19: 1371-1389.

7. Levey JM, Banner BF. Adult pancreatoblastoma: A case report and review of the literature. Am J Gastroenterol 1996; 91: 1841-1844.

8. Palosaari D, Clayton F, Seaman J. Pancreatoblastoma in an adult. Arch Pathol Lab Med 1986; 110: 650-652.

9. Robin E, Terris B, Valverde A, et al. [Pancreatoblastoma in adults]. GastroenterolClinBiol 1997; 21: 880-883.

10. Mumme T, Buttner R, Peiper C, et al. [Pancreatoblastoma: A rare malignant neoplasm in early adulthood]. Chirurg 2001; 72: 806-811. 
11. Benoist S, Penna C, Julie C, et al. Prolonged survival after resection of pancreatoblastoma and synchronous liver metastases in an adult. Hepatogastroenterology 2001; 48: 1340-1342.

12. Gruppioni F, Casadei R, Fusco F, et al. Adult pancreatoblastoma: A case report. Radiol Med (Torino) 2002; 103: 119-122.

13. 13.Rajpal S, Warren RS, Alexander M, Yeh BM, et al. Pancreatoblastoma in an Adult: Case Report and Review of the Literature. J of GastrointestSurg 2006; 10: 829-36.

14. Zhu L, Sidhu G, Cassai N, Yang G. Fine-needle aspiration cytology of pancreatoblastoma in a young women: report of a case and review of literature. DiagnCytopathol 2005; 33: 258-62.

15. Montemarano H, Lonergan GJ, Bulas DI, et al. Pancreatoblastoma: Imaging findings in 10 patients and review of the literature. Radiology 2000; 214: 476-482.

16. Balasundaram C, Luthra M, Chavalitdhamrong D, Chow J, Khan H, Endres PJ.Pancreatoblastoma: a rare tumor still evolving in clinical presentation andhistology.JOP. 2012: 3; 301-303.

\section{AUTHORS:}

1. G. Ray

2. S. P. Venkatesh

3. S. Ilayalvan

4. S. Sowmya

5. E. Nidhya

\section{PARTICULARS OF CONTRIBUTORS:}

1. Associate Professor, Department of Surgery, Sri Manakula Vinayagar Medical College and Hospital.

2. Assistant Professor, Department of Surgery, Sri Manakula Vinayagar Medical College and Hospital.

3. Professor, Department of Surgery, Sri Manakula Vinayagar Medical College and Hospital.

4. Professor, Department of Pathology, Sri Manakula Vinayagar Medical College and Hospital.
5. Post Graduate Student, Department of Pathology, Sri Manakula Vinayagar Medical College and Hospital.

\section{NAME ADDRESS EMAIL ID OF THE CORRESPONDING AUTHOR:}

\section{Dr. G. Ray,}

Associate Professor,

Department of Surgery,

Sri Manakula Vinayagar Medical College

\& Hospital,

Kalitheerthalkuppam,

Pondicherry-605107.

Email: srivatsanray@yahoo.com

Date of Submission: 01/09/2014.

Date of Peer Review: 02/09/2014.

Date of Acceptance: 12/09/2014.

Date of Publishing: 22/09/2014. 